\title{
Living longer and breathing better: Should we do transcatheter aortic valve replacement in patients who have severe chronic lung disease?
}

\author{
Juan A. Crestanello, MD
}

\author{
From the Division of Cardiac Surgery, The Ohio State University Wexner Medical Center, Columbus, Ohio. \\ Disclosures: Author has nothing to disclose with regard to commercial support. \\ Received for publication Oct 21, 2015; accepted for publication Oct 22, 2015; available ahead of print Nov 19, \\ 2015. \\ Address for reprints: Juan A. Crestanello, MD, Division of Cardiac Surgery, Wexner Medical Center, N-820 Doan \\ Hall, 410 W 10th Ave, Columbus, OH 43210 (E-mail: juan.crestanello@osumc.edu). \\ J Thorac Cardiovasc Surg 2016;151:587-8 \\ $0022-5223 / \$ 36.00$ \\ Copyright (C) 2016 by The American Association for Thoracic Surgery \\ http://dx.doi.org/10.1016/j.jtcvs.2015.10.087
}

Symptoms of severe aortic stenosis and of chronic lung disease (CLD) are similar, and very difficult to differentiate from each other. The distinction between the 2 is important, because relieving aortic stenosis may not benefit patients whose symptoms are predominantly secondary to CLD; and doing so will subject them to a risky and potentially unnecessary procedure. Historically, only a relatively small number of patients with aortic stenosis and severe CLD have been treated with surgical AVR. ${ }^{1}$ Early outcomes of these patients were worse than those of patients who had a lesser degree of pulmonary impairment. They had increases in rates of hospital mortality, perioperative morbidities, and length of hospital stay. ${ }^{1,2}$ The long-term outcomes of these patients after surgical AVR are less well characterized, ${ }^{2}$ but seems to be associated with decreased long-term survival.

Transcatheter AVR (TAVR) has less of an impact on pulmonary physiology, because it avoids median sternotomy, cardiopulmonary bypass, and the pulmonary derangements associated with surgical AVR. Use of TAVR extended the option for treatment of aortic stenosis to include sicker patients; as a result, more patients with severe and even "very severe" lung disease are being treated. In the Society for Thoracic Surgeons database, only 3\% of patients were oxygen dependent, and only $4.5 \%$ had severe CLD; yet, the rate of oxygen dependency and severe CLD in patients treated with TAVR in the Transcatheter Valve Therapy registry increased, to $14 \%$ and $13.6 \%$, respectively. ${ }^{1,3,4}$

Despite the increased use of TAVR in more patients with severe chronic lung disease, several questions remain: Do they benefit from TAVR? If they do, how do we define benefit in these patients? Based on that definition, how do we identify those patients before the procedure?

Henn and colleagues ${ }^{5}$ have contributed to our understanding of the impact of chronic lung disease on 1-year mortality after surgical AVR and TAVR. They have shown that chronic lung disease has a dose-dependent adverse effect on 1-year mortality. This effect was seen when patients were stratified by Society for Thoracic Surgeons CLD severity, \%

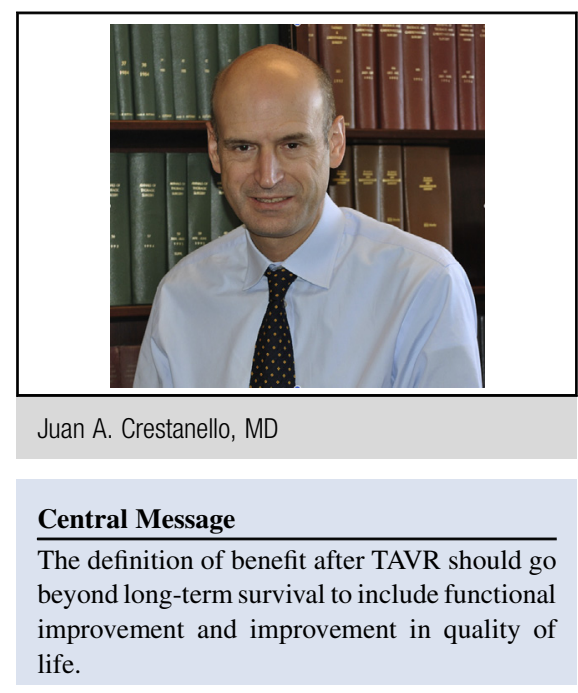

See Article page 578 .

predicted forced expiratory volume in 1 second $\left(\mathrm{FEV}_{1}\right)$, and diffusing capacity of the lungs for carbon monoxide (DLCO) quartiles, as well as when these 2 measures were analyzed as continuous variables. Severe CLD, or FEV 1 and DLCo in the lower quartile of $\%$ predicted, were associated with a 1-year mortality greater than $30 \%$.

These results are in agreement with the recent, published data from the Transcatheter Valve Therapy registry, including $>12,000$ patients treated with TAVR. In this comprehensive registry, severe chronic obstructive pulmonary disorder was associated with a 1-year mortality of $32 \%$ after TAVR. ${ }^{3,4}$ The adverse effect of lung disease on 1-year mortality outcomes is important to understand to appropriately counsel patients before TAVR procedures.

The definition of benefit after TAVR should go beyond mid- and long-term survival or mortality. Taken in isolation, being alive or dead is not always equivalent to success or failure. For example, patients who died in the first year after TAVR may have benefited by avoiding rehospitalizations or by improvement in heart failure symptoms and quality of life during their final year. Conversely, patients who are still alive may have such a bad quality of life that it decreases the benefit of being alive. Therefore, other meaningful outcomes such as quality of life, functional improvement, independent living arrangements, and freedom from rehospitalization should be included, along with survival, in the definition of success after TAVR. These factors will become more and more important to help clinicians make objective 
decisions about treatment. Unfortunately, that essential information is not easily obtained from retrospective studies or registries and was not reported in the current article.

Finally, the characteristics of patients with severe or very severe pulmonary disease who benefit from TAVR, as defined above, are not well defined. Further characterization of their outcomes is essential and needs to be based on preprocedural spirometry data, arterial blood gas data, and other clinical and functional parameters, to clearly identify those patients who would benefit from TAVR. Both "living longer" and "breathing better" should be the ultimate measures of success in the treatment of patients who have CLD and aortic stenosis. The answer to the question in the title of this commentary is still unknown.

\section{References}

1. Crestanello JA, Higgins RS, He X, Saha-Chaudhuri P, Englum BR, Brennan JM, et al. The association of chronic lung disease with early mortality and respiratory adverse events after aortic valve replacement. Ann Thorac Surg. 2014;98: 2068-77.

2. Gunter RL, Kilgo P, Guyton RA, Chen EP, Puskas JD, Cooper WA, et al. Impact of preoperative chronic lung disease on survival after surgical aortic valve replacement. Ann Thorac Surg. 2013;96:1322-8.

3. Suri RM, Gulack BC, Brennan JM, Thourani VH, Dai D, Zajarias A, et al. Outcomes of patients with severe chronic lung disease who are undergoing transcatheter aortic valve replacement. Ann Thorac Surg. 2015 [Epub ahead of print].

4. Holmes DR Jr, Brennan JM, Rumsfeld JS, Dai D, O'Brien SM, Vemulapalli S, et al; STS/ACC TVT Registry. Clinical outcomes at 1 year following transcatheter aortic valve replacement. JAMA. 2015;313:1019-28.

5. Henn MC, Zajarias A, Lindman BR, Greenberg JW, Melby SJ, Quader N, et al. Preoperative pulmonary function tests predict mortality after surgical or transcatheter aortic valve replacement. J Thorac Cardiovasc Surg. 2016; 151:578-86.e1-3. 